\title{
Genangan Banjir Rob Di Kecamatan Semarang Utara
}

\author{
Gentur Handoyo, Agus A.D. Suryoputro, Petrus Subardjo
}

Depa rtement Ilmu Kela utan, Fakultas Perikanan dan Ilmu Kelautan, Universitas Diponegoro JI. Prof. Soedarto, SH. Kampus UNDIP Tembalang, Semarang 50275

Email : genturhandoyo@yahoo.com

\begin{abstract}
Abstrak
Kota Semarang yang memiliki wilayah Pesisir di bagian utara adalah daerah yang terkena dampak kenaikan muka laut. Dampak utama yang diakibatkan oleh kenaikan permukaan air laut adalah terjadinya banjir pasang. Kecamatan Semarang Utara menupakan salah satu tempat di Kota Semarang yang sering dilanda banjir rob. Tujuan penelitian ini adalah untuk mengetahui kondisi genangan rob di Kecamatan Semarang Utara. Metode yang digunakan adalah metode admiralty, sedangkan peramalan pasang surut menggunakan software Mike 21 . Model genangan rob dibuat berdasarkan nilai HHWL tahunan yang dikoreksi dengan MSL tahunan. Berdasarkan hasil model genangan rob, luas genangan banjir rob di Kecamatan Semarang Utara yang terjadi pada tahun 2014 menc a pai 823.545 ha atau 70,991\% dari luas wilayah Kecamatan Semarang Utara.
\end{abstract}

Kata Kunci: Banjir Rob, Mike 21, Kecamatan Semarang Utara

\begin{abstract}
Abstact
Semarang city which has a coastal region in the nort, is clearly of feed by sea level rise. The major in pacts caused by sea level rise is the occurrence of fooding. Northem districts of Semarang is one of the places in the city of this study is to distribution of inundation which formed in the northem districts of semarang. The analysis using admiralty method whereal tidak forecasting was done using software mike 21. The model wa made based upon the value of the corrected annual HHWL and annual MSL. Based on the results of model of imidation, estensive tidak flood waters in the northerm district of Semarang which occured in 2014 reached 823,545 ha or $70,991 \%$ of the area of the northem district of Semarang.
\end{abstract}

Keywords: Tidal Inundation, Mike 21, Northem distric ts of Sema rang

\section{PENDAHULUAN}

Semarang merupakan salah satu Kota yang terletak di wilayah pantai Utara Pulau Jawa. Menunut Lubis et al. dalam Nugroho (2013) secara geografis Kota Semarang terletak pada garis 6050' - 7010' LS dan garis $109^{\circ} 35^{\prime}$ - $110^{\circ} 50^{\prime}$. Wilayah pesisir Semarang memiliki topografi yang landau dengan sebagian besar wilayahnya hamper sama tingginya dengan permukaan laut (BAPPEDA dalam Ramadhany et al. (2011). Sedangkan ditambahkan oleh Sarbi di (2002) bahwa Kota Semarang memiliki wilayah pesisir dengan garis panta i sepanjang $\pm 13,6 \mathrm{KM}$. Wilayah pesisir Kota Semarang terjadi banjir rob yang diakibatkan oleh kenaikan permukaan a ir laut. Menurut Nicholls et al. dalam Nugroho (2013), banjir rob yang disebabkan air laut pasang inilah yang dalam kurun waktu \pm 25 th terakhir terjadi di kawasan pesisir Sema rang.

Menurut Ismanto et al. (2009), banjir rob yang menggenangi beberapa tempat di pesisir Kota Semarang pada bulan Mei 2005 tercatat ada 14 kelurahan yang tergenang rob. Beberapa kelurahan tersebut selain letaknya yang berada di tepi Pantai Utara Jawa juga letaknya berada disepanjang daerah aliran sungai (Astuti, 2009). Selanjutnya dikatakan bahwa rob atau air pasang laut itu masuk 
ke wilayah pesisir Kota Semarang melalui tiga sungai utama yaitu Kali Semarang, Kali Baru dan Kali Banger.

Menurut Astuti (2009) Kecamatan Semarang Utara menupakan salah satu tempat di Kota Semarang yang sering terkena genangan rob. Berdasarkan pengamatan lapangan banyak bangunan yang tergenang dibandingkan dengan kecamatan-kecamatan lain di Kota Semarang. Berdasarkan uraian tersebut diatas maka penelitian ini bertujuan untuk mengetahui genangan banjir rob di Kecamatan Semarang Utara.

\section{MATERI DAN METODE}

Penelitian ini dilaksanakana di Kecamatan Semarang Utara pada bulan Februari 2014. Data yang diperlukan adalah data pasang surut, data tinggi genangan rob, data ketinggian / topografi.

I. Pengambilan Data Lapangan

a. Pengamatan Pasang Surut

Diukur ketinggian muka air laut menggunakan palem pasut pada setiap interwat 60 menit dengan rentang waktu pengamatan selama 15 hari.

b. Pengukuran Tinggi Ba njir Rob Pengukuran tinggi banjir rob dilakukan pada 8 titik lokasi di Kecamatan Semarang Utara yang sering mengalami banjir rob saat terja di pasang a iar laut tertinggi.

II. Analisa Data

a. Analisa Hamonik Pasang Surut Analisa hamonik menggunakan metode admiralty, yaitu analisa pasang surut yang digunakan untuk menghitung data konstanta hamonik yaitu amplitude dan kelambatan fase.

Setelah didapat nilai amplitude dan kelambatan fase, selanjutnya dihitung :

1. Tinggi muka air rata-rata (Mean Sea Level) MSL : A (So)

2. Tinggi Muka Air Tinggi Tertinggi (High Highest Water Level)
HHWL : $\mathrm{A}(\mathrm{SO})+\left\{\mathrm{A}\left(\mathrm{M}_{2}\right)+\mathrm{A}\left(\mathrm{S}_{2}\right)\right.$ $+A\left(K_{1}\right)+A\left(O_{1}\right)+A\left(K_{2}\right)+$ $\left.A\left(P_{1}\right)\right\}$

3. Tinggi Muka air rendah terendah (Low Lowes Watex Level)

LLWL: $A\left(S_{0}\right)-\left\{A\left(M_{2}\right)+A\left(S_{2}\right)+\right.$ $\left.\mathrm{A}\left(\mathrm{K}_{1}\right)+\mathrm{A}\left(\mathrm{O}_{1}\right)+\mathrm{A}\left(\mathrm{K}_{2}\right)+\mathrm{A}\left(\mathrm{P}_{1}\right)\right\}$

4. Tipe pasang surut di daerah penelitian

$$
F=\frac{K_{1}+O_{1}}{M_{2}+S_{2}}
$$

Klasifikasi tipe pasang surut $0<\mathrm{F}<0,25$ Pa sut ha rian ganda $0,25<\mathrm{F}<1,5$ Pasut campuran condong ke harian ganda 1,5 $<\mathrm{F}<3$ Pasut Campuran condong ke harian tunggal $\mathrm{F}>3$ Pasut harian tunggal

III. Analisa Peramalan Pasang Surut Metode yang digunakan untuk peramalan pasang surut adalah metode Least Square yang terdapat pada software MIKE 21 Toolbox Modul Tidal Ana lysis and Prediction

IV. Uji Kesesuaian Model

Uji Kesesuaian Model meru[akan suatu tahap pengecekan model untuk membuktikan bahwa hasil model sudah sesuai dengan kondisi sebenamya.

Persamaannya adalah Mean Relative Error (MRE)

$\mathrm{RE}=\left|\frac{\text { HPeramalan }- \text { HPengamatan }}{\text { HPengamatan }}\right| \times 100 \%$

$M R E=\frac{\sum R E}{n}$

Dimana : $\mathrm{n} \quad=$ Jumlah data RE = Relative Error

V. Pembuatan Data DEM

DEM atau Digital Elevation Model merupakan data digital informasi koordinat posisi $(x, y)$ data DEM berasal dari data ketinggian yang diperoleh dari data titik tinggi (Budiyanto, 2005). Metode yang digunakan untuk pembentukan DEM 
menggunakan Metode Spatial Analyst dengan tools to Raster yang terdapat pada software Arc GIS 10.1 Lokasi pengukuran titik tinggi dapat dilihat pada Gambar 1.

VI. Pembuatan Model Banjir Rob

Proses pembentukan model spatial banjir rob dilakukan dengan menggunakan metode spatial Analyst dengan tools Raster Calculator yang terdapat pada software Arc GIS 10.1

\section{HASILDAN PEMBAHASAN}

Model banjir rob dibuat dalam skenario banjir rob akibat pengaruh pasang tertinggi pada tahun 2015. Hasil model banjir rob dapat dilihat pada Gambar 2. Berdasarkan gambar 2, luas banjir rob seluas 823.545 ha. Hampir seluruh kelurahan di Kecamatan Semarang Utara meliputi Kelurahan Tanjung Mas, Kelurahan Bandarharjo, kelurahan Panggung Lor, Kelurahan Kuningan, Kelurahan Panggung Kidul dan Kelurahan Plombokan terkena dampak dari adanya banjir rob. Luas banjir rob yang terjadi di tiap kelurahan dapat dilihat pada Tabel 1 .
Pembuatan model genangan banjir rob berdasarka n nila i HHWL ta hunan HHWL tahunan, dihasilkan luas genangan rob seluas 823.545 ha (lihat tabel 1). Sementara luas Kecamatan Utara $1160.0608 \mathrm{Ha}$, sehingga luas genangan banjir rob sekitar $70,99 \%$ dari luas Kecamatan Semarang Utara (Tabel2).

Berdasarkan model genangan banjir rob (gambar 2), terlihat hampir seluruh kelurahan di Kecamatan Semarang Utara terkena dampak dari banjir rob. Hal tersebut disebabkan kelurahan-kelurahan tersebut berada di pesisir Semarang yang berbatasan langsung dengan laut dan memiliki ketinggian tanah yang rendah dengan ketinggian kurang dari 0,5 meter diatas permukaan laut.

Tiga kelurahan yang belum tergenang banjir rob yaitu Kelurahan Purwosari, Kelurahan Bulu Lor dan Kelurahan Dadapsari. Hal tersebut disebabkan karena letaknya yang berada jauh dari wilayah pesisir Semarang, topografi pada kelurahan tersebut cukup tinggi dengan ketinggian berkisar antara 1-10 meter diatas permukaan laut. Menurut Diposartono et al. (2009), salah satu parameter yang mempengaruhi

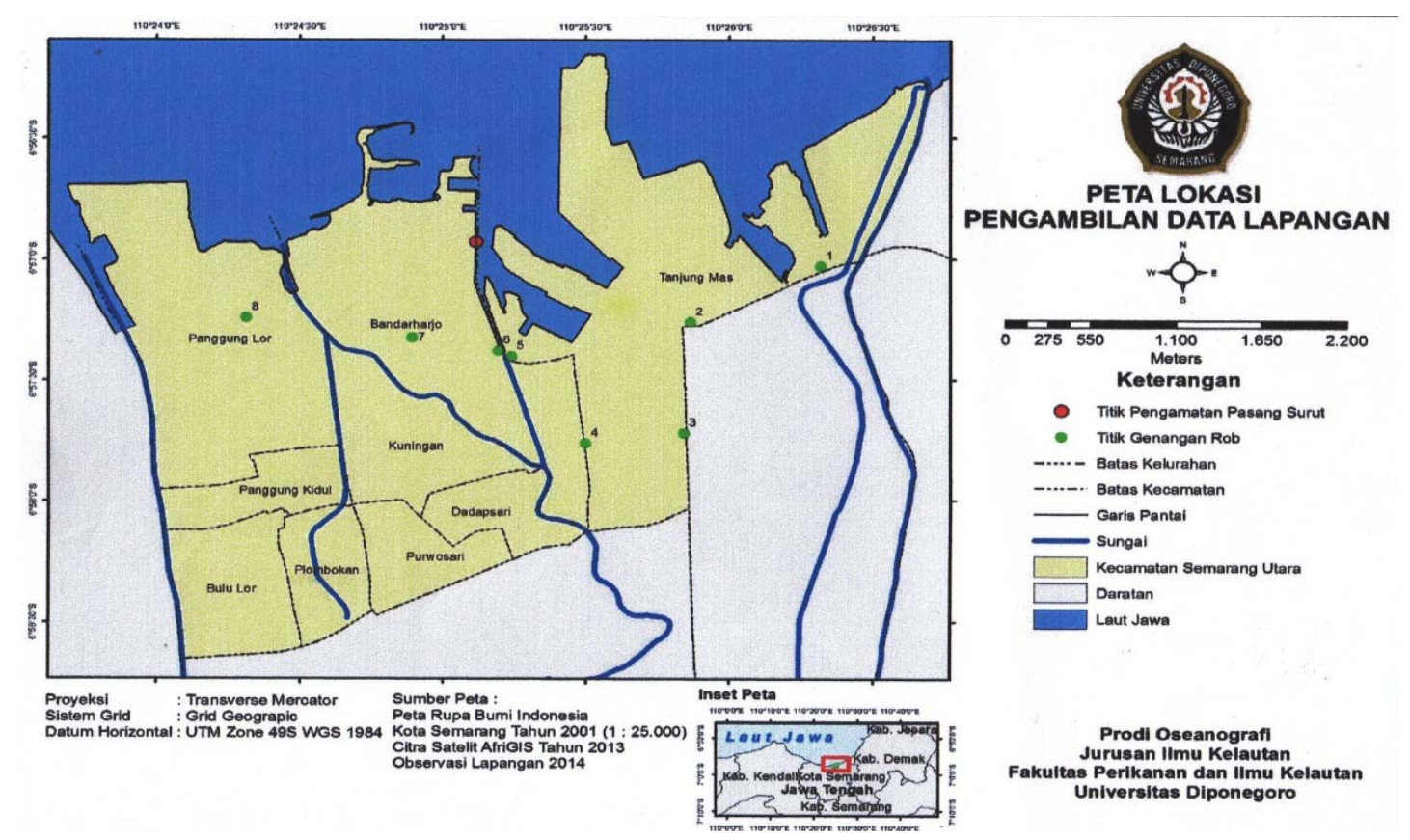

Gambar 1. Peta Lokasi Pengambilan Data Lapangan 
Tabel 1. Luas genangan banjir rob pada tiap Kelurahan

\begin{tabular}{clr}
\hline No. Kelurahan & Luas Banjir Rob $(\mathrm{Ha})$ \\
\hline 1. & Tanjung Mas & 337.06 \\
2. & Panggung Lor & 208.808 \\
3. & Bandarharjo & 197.286 \\
4. & Kuningan & 61.537 \\
5. & Panggung Kidul & 18.462 \\
6. & Plombokan & 0,392 \\
\hline & Total & 823.545 \\
\hline
\end{tabular}

Sumber : Hasil Penelitian

Tabel 2. Rekapitulasi prosentase luasa genangan rob tiap kelurahan

\begin{tabular}{lllrr}
\hline No & \multicolumn{1}{c}{ Kelurahan } & $\begin{array}{c}\text { Luas Wilayah } \\
\text { (ha) }\end{array}$ & $\begin{array}{c}\text { Luas Genangan } \\
\text { Rob (ha) }\end{array}$ & $\begin{array}{r}\text { Prosentase Wilayah } \\
\text { Tergenang (\%) }\end{array}$ \\
\hline 1 & Tanjung Mas & 364,404388 & 337,06 & 92,496 \\
2 & Panggung Lor & 233,215947 & 208,808 & 89,534 \\
3 & Bandarharjo & 219,762875 & 197,286 & 89,772 \\
4 & Kuningan & 85,056094 & 61,537 & 72,349 \\
5 & Bulu Lor & 75,438019 & - & - \\
6 & Purwosari & 47,782697 & - & - \\
7 & Plombokan & 47,743502 & 0,342 & 39,821 \\
8 & Panggung Kidul & 46,924908 & 18,462 & - \\
9 & Dadapsari & 39,732452 & - & 70,991 \\
\hline
\end{tabular}
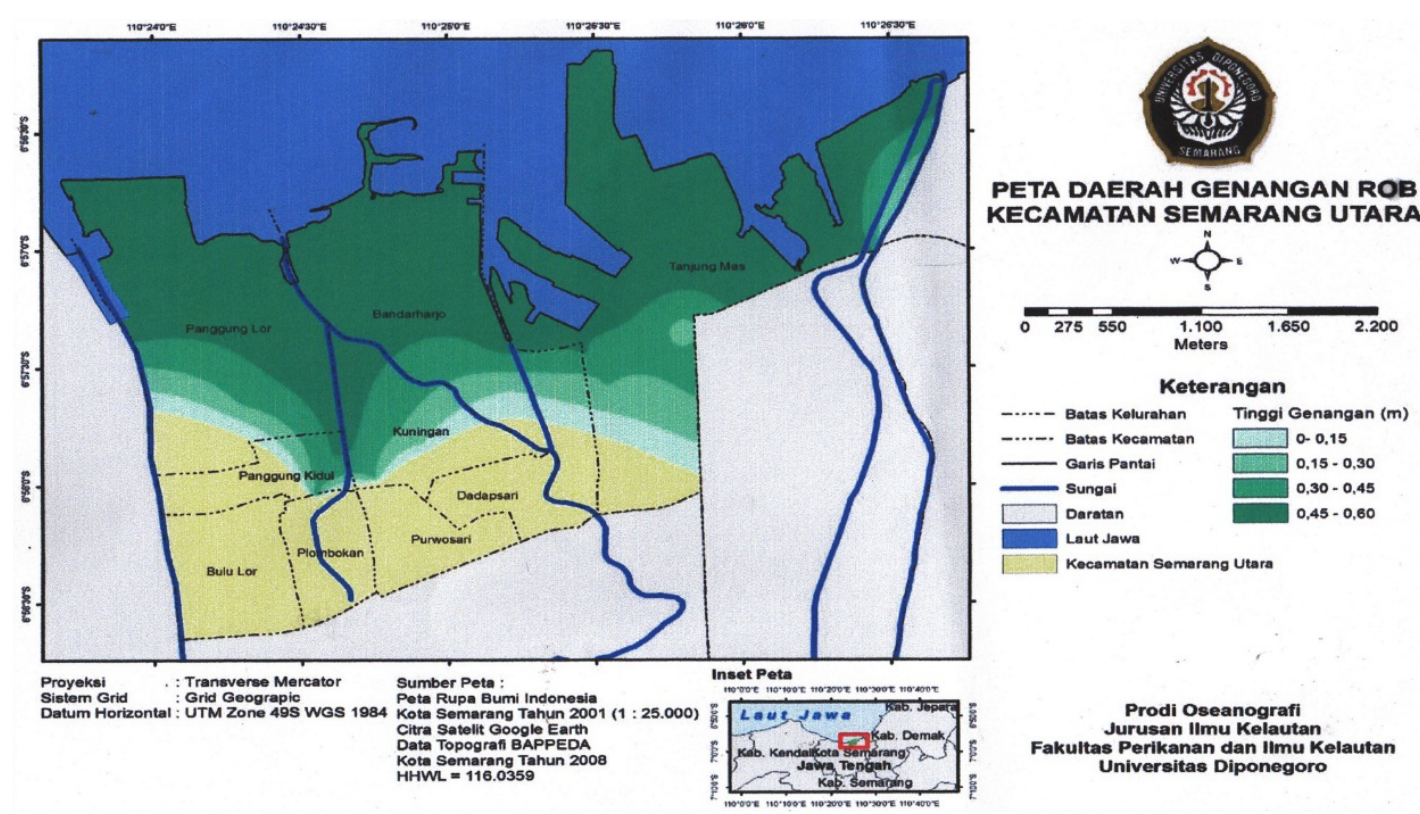

Gambar 2. Peta Daerah Genangan Rob di Kecamatan Semarang Utara

daerah genangan rob selain sea level rise adalah ketinggian tanah. Ketinggian tanah yang landai berpengaruh dalam pembentukan genangan rob, sehingga apabila ketinggian tanah lebih rendah daripada muka a ir laut ketika air pasang maka daerah yang landai akan tergenang. 


\section{KESIMPULAN}

Luas banjir rob di Kecamatan Semarang Utara pada tahun 2014 akibat kenaikan muka a ir laut seluas 823,545 ha. Kelurahan Tanjung Mas merupakan kelurahan yang paling luas terkena dampak dari banjir rob dengan luas mencapai 337,06 ha dengan prosentase luas banjir rob $92,496 \%$

\section{DAFIAR PUSTAKA}

Ali, M.D.K. Mihardja dan S. Hadi.1994. Pasang Surut Laut. ITB. Bandung

Astuti, Sri. 2009. Reklamasi Tipologi Bangunan dan Kawasan Akibat Pengaruh Kenaikan Muka Air Laut di Kota Pantai Semarang. Departmene Kim Praswil, Bandung.

Bakti, L. M. 2010. Kajian Sebaran Potensi Rob Kota Semarang dan Usulan Penanganannya (Tesis). Program Studi
Masgister Teknik Sipil. Universitas Diponegoro Semarang.

Budiyanto, E. 2005. Sistem Informasi Geografis Mengguna kan Arc View GIS. Penerbit Andi, Yogyakarta.

Diposaptono, S. Budiman dan Firdaus, A. 2009. Menyiasati Perubahan Iklim di Wilayah Pesisir dan Pulau-Pulau Kecil. Penerbit Buku llmiah Populer, Bogor.

Ismanto, A., A. Wirasatriya, M. Helmi, A. Hartoko dan Prayogi. 2009. Model Sebaran Penununan Tanah di Wilayah Pesisir Semarang. J umal Ilmu Kelautan Vol 14. No. 4 Desember 2009 : 21-28.

Nugroho, S.H. 2013. Prediksi Luas Genangan Pasang Surut (Rob) Berdasarkan Analisis data Spasial di Kota Semarang, Indonesia. Jumal Lingkungan dan Bencana Geologi Vol. 40 No. 1. April $2013: 71-87$

Ramadhany, A.S., A Anugroho dan P. Subardyo. 2011. Daerah Rawa Genangan Rob di Wilayah Semarang. J umal Ilmu Kelautan Vol. 1 No. 2. 2012 : $174-180$ 